STUDI

FRANCESI

\section{Studi Francesi}

Rivista quadrimestrale fondata da Franco Simone

145 (XLIX | I) | 2005

Varia - fasc. I - gennaio-aprile 2005

\title{
Alain Cullière, La mort du comédien Adrien Talmy (1603)
}

\section{Filippo Fonio}

\section{(2) OpenEdition}

1 Journals

\section{Edizione digitale}

URL: http://journals.openedition.org/studifrancesi/35973

DOI: 10.4000/studifrancesi.35973

ISSN: 2421-5856

\section{Editore}

Rosenberg \& Sellier

\section{Edizione cartacea}

Data di pubblicazione: 1 juillet 2005

Paginazione: 152

ISSN: 0039-2944

\section{Notizia bibliografica digitale}

Filippo Fonio, «Alain Cullière, La mort du comédien Adrien Talmy (1603)», Studi Francesi [Online], 145 (XLIX | I) | 2005, online dal 30 novembre 2015, consultato il 18 avril 2021. URL: http://

journals.openedition.org/studifrancesi/35973 ; DOI: https://doi.org/10.4000/studifrancesi.35973

Questo documento è stato generato automaticamente il 18 avril 2021.

\section{(c) (i) (9)}

Studi Francesi è distribuita con Licenza Creative Commons Attribuzione - Non commerciale - Non opere derivate 4.0 Internazionale. 


\title{
Alain Cullière, La mort du comédien Adrien Talmy (1603)
}

\author{
Filippo Fonio
}

\section{NOTIZIA}

ALAIN CULLIÈRE, La mort du comédien Adrien Talmy (1603), «Bibliothèque d'Humanisme et Renaissance», LXV, 3 (2003), pp. 601-612.

1 Lo studioso tenta di ricostruire in base alla scarsissima documentazione disponibile gli spostamenti di alcuni commedianti fra i più noti alla fine del XVI sec.: Châteauvieux (Polidor), capocomico e valletto di camera del re, titolo onorifico che consente anche a chi lo porta di agire in qualità di informatore; Valleran Le Conte, la cui attività può essere a tratti ricostruita nel periodo 1592-1615; Adrien Talmy, l'unico del quale si conosca il repertorio. Sulle scene dal 1593 circa, si hanno notizie della sua compagnia a Cambrai e ad Arras, con tragedie di Robert Garnier, moralità e pastorali. Nel 1598 costituisce un'associazione di breve durata con il più celebre Valleran Le Conte, il che apre a Talmy le porte dei palchi parigini. Lo si trova quindi a Nancy, nei Paesi Bassi spagnoli, a Tournai dove la sua compagnia deve scontrasi con l'ostilità del vescovo, a Saint-Omer. Si possiede inoltre un importante documento a proposito di Talmy, un atto notarile che ne attesta la morte avvenuta a Metz nel 1603, in misere condizioni economiche. Fin dal Medioevo la città di Metz concedeva mezzi e spazi all'attività teatrale, legata verso la fine del XVI sec. al collegio municipale, alle cerimonie in occasione della création des Etats e in particolare alla presenza in città di una sala della fine del XV sec., che poteva essere presa a nolo e solitamente adibita alla celebrazione di cerimonie, alle assemblee della cittadinanza e all'allestimento di spettacoli. Nei registri inerenti l'affitto di questa sala non si trova però traccia di Talmy, dal che si può dedurre che ai primi del XVII sec. egli risiedesse a Metz avendo abbandonato la propria attività teatrale - come confermato dall'atto qui riprodotto e datato all'aprile 1603, concernente l'insolvenza di un debito contratto da Talmy e per il quale egli ha messo in pegno le attrezzature di scena. Una postilla all'atto in questione, datata al giugno dello 
stesso anno, attesta l'avvenuta morte del commediante e l'impossibilità da parte della vedova di soddisfare il creditore. 